\title{
Association of endothelial nitric oxide synthase polymorphisms and haplotypes with ischemic stroke in Korean individuals with or without diabetes mellitus
}

\author{
OK JOON KIM ${ }^{1,3^{*}}$, UN-KYUNG KIM ${ }^{4 *}$, SEUNG HUN OH ${ }^{1}$, YONG WOOK $\mathrm{CHO}^{2}, \mathrm{KYUNG} \mathrm{IM} \mathrm{OH}^{3}$, \\ DOYEUN OH ${ }^{2,3}$, YOUNG SEOK PARK ${ }^{5}$ and NAM KEUN KIM ${ }^{3}$
}

Departments of ${ }^{1}$ Neurology, and ${ }^{2}$ Internal Medicine, ${ }^{3}$ The Institute for Clinical Research, School of Medicine, CHA University, Seongnam; ${ }^{4}$ Department of Biology, College of Natural Sciences, Kyungpook National University, Daegu;

${ }^{5}$ Department of Neurosurgery, Yonsei University College of Medicine, Seoul, Korea

Received January 12, 2010; Accepted March 15, 2010

DOI: $10.3892 / \mathrm{mmr} 00000289$

\begin{abstract}
Polymorphisms of the endothelial nitric oxide synthase (eNOS) gene have been implicated in various diseases associated with cardiovascular risk factors, but little is known regarding the risks of ischemic stroke (IS) in patients with diabetes mellitus (DM). In this study, we evaluated the genotypes and haplotypes of three eNOS polymorphisms $(-786 \mathrm{~T}>\mathrm{C}, 4 \mathrm{a} 4 \mathrm{~b}$ and $894 \mathrm{G}>\mathrm{T})$ in a Korean population of 223 IS patients and 206 controls classified into four groups: healthy subjects, type $2 \mathrm{DM}$ patients without IS, IS patients without type $2 \mathrm{DM}$ and IS patients with type $2 \mathrm{DM}$. The genotype frequency of $4 \mathrm{a} 4 \mathrm{~b}$ in the controls with type $2 \mathrm{DM}$ differed significantly from that in the controls without DM (4b4b vs. $4 \mathrm{a} 4 \mathrm{~b} ; \mathrm{OR}=2.769 ; 95 \% \mathrm{CI} 1.233-6.220$ ). and the frequency of the $-786 \mathrm{C}-4 \mathrm{a}-894 \mathrm{G}$ haplotype was higher in the controls with DM compared to the controls without DM ( $\mathrm{P}=0.040)$. Additionally, the $-786 \mathrm{C}-4 \mathrm{~b}-894 \mathrm{G}$ haplotype was more common in the cases with DM than in the controls without type $2 \mathrm{DM}(\mathrm{P}=0.034)$. Our findings suggest that the eNOS $4 \mathrm{a}$ allele-associated genotype and haplotype is a risk factor for type $2 \mathrm{DM}$, and that the $-786 \mathrm{C}-4 \mathrm{~b}-894 \mathrm{G}$ haplotype is a risk factor for IS with DM.
\end{abstract}

\section{Introduction}

Ischemic stroke (IS) is a leading cause of death and disability in the developed world, and is known to be a multi-factorial disorder caused by a combination of genetic and environ-

Correspondence to: Dr Nam Keun Kim, The Institute for Clinical Research, School of Medicine, CHA University, 351 Yatap-dong, Bundang-gu, Seongnam 463-712, Korea

E-mail:nkkim@cha.ac.kr; namkkim@naver.com

${ }^{*}$ Contributed equally

Key words: endothelial nitric oxide synthase, ischemic stroke, diabetes mellitus, polymorphism, haplotype mental risk factors (1-2). For example, type 2 diabetes mellitus (DM) is associated with a 2- to 5-fold increased risk for first or recurrent IS (3-5). The mechanisms behind the association are myriad, and include the effects of hyperglycemia on vascular tissues and coagulation, as well as aberrations in blood pressure regulation, endothelial function, lipid metabolism, vascular inflammation, lipid metabolism and smooth muscle cell proliferation.

Nitric oxide (NO) is produced from L-arginine by endothelial nitric oxide synthase (eNOS) and is involved in vessel homeostasis by inhibiting vascular smooth muscle contraction and growth, platelet aggregation and leukocyte adhesion to the endothelium (6-8). Endothelial dysfunction is related to alternating vascular reactivity and vasospasm by diminished NO production leading to the impaired vasodilation of arteries, and is known to be associated with cardiovascular risk factors such as stroke, type $2 \mathrm{DM}$ and atherosclerosis (9-11). Moreover, since abnormalities in the activity of eNOS affecting the level of plasma NO have been identified, the eNOS gene is a possible candidate gene for susceptibility to stroke (12). Several single nucleotide polymorphisms (SNPs) in this gene have been identified, of which three polymorphisms $(-786 \mathrm{~T}>\mathrm{C}$ located in the promoter of the eNOS gene, a 27-bp repeat polymorphism in intron 4 and $894 \mathrm{G}>\mathrm{T}$ in exon 7) have been shown to be associated with IS (13-17). Most of these studies examined the association of these SNPs with DM or IS individually; little is known regarding the effect of SNPs in the eNOS gene on the susceptibility to IS of patients with DM. Here, we evaluated the eNOS genotype and haplotype distribution of the most relevant polymorphisms $(-786 \mathrm{~T}>\mathrm{C}$, $4 \mathrm{a} 4 \mathrm{~b}$ and $894 \mathrm{G}>\mathrm{T}$ ) in a Korean population classified into four groups: healthy subjects, type 2 DM patients without IS, IS patients without type $2 \mathrm{DM}$, and IS patients with type $2 \mathrm{DM}$.

\section{Materials and methods}

Subjects. The study subjects included 223 IS patients (including 67 type 2 DM patients) and 206 control subjects without IS (including 36 type 2 DM patients) (Table I). The IS patients were recruited upon enrollment at the Department 
Table I. Demographic and clinical characteristics of ischemic stroke patients and controls.

\begin{tabular}{|c|c|c|c|c|c|c|}
\hline \multirow[t]{2}{*}{ Characteristics } & \multicolumn{3}{|c|}{ Subjects without IS } & \multicolumn{3}{|c|}{ Subjects with IS } \\
\hline & $\begin{array}{c}\text { Controls } \\
\text { (no DM; } n=170 \text { ) }\end{array}$ & $\begin{array}{c}\text { Subjects } \\
\text { (with DM; } n=36 \text { ) }\end{array}$ & P-value & $\begin{array}{c}\text { Controls } \\
\text { (no DM; } \mathrm{n}=156)\end{array}$ & $\begin{array}{c}\text { Subjects } \\
\text { (with DM; } n=67 \text { ) }\end{array}$ & P-value \\
\hline Male (\%) & $84(49.4)$ & $23(63.9)$ & 0.142 & $92(59.0)$ & $37(55.2)$ & 0.658 \\
\hline Age (years) & $59.89 \pm 0.85$ & $61.28 \pm 1.82$ & 0.495 & $61.09 \pm 0.91$ & $63.58 \pm 1.24$ & 0.123 \\
\hline Smokers $(\%)$ & $16(9.4)$ & 7 (19.4) & 0.140 & $23(14.7)$ & $9(13.4)$ & 1.000 \\
\hline Hyperlipidemia (\%) & $19(11.2)$ & $15(41.7)$ & $<0.0001$ & $46(29.5)$ & $36(53.7)$ & 0.001 \\
\hline Hypertension (\%) & $82(48.2)$ & $25(69.4)$ & 0.027 & $107(68.6)$ & $48(71.6)$ & 0.751 \\
\hline
\end{tabular}

IS, ischemic stroke; DM, diabetes mellitus.

of Neurology at Bundang CHA General Hospital between November 2003 and June 2005 by consecutive referral. IS was defined as a stroke, i.e., a clinical syndrome characterized by rapidly developing clinical symptoms and signs of focal and at times global loss of brain function, with evidence of a cerebral infarction in the clinically relevant area of the brain by a brain imaging study.

The diagnosis of IS was made when neurologic deficits were accompanied by corresponding abnormal magnetic resonance imaging (MRI) findings of the brain, which were interpreted by two independent experienced neurologists. An IS patient was excluded when researchers did not reach agreement. Patients with cerebral hemorrhage were excluded in advance. Examinations were performed with a 1.5-T superconducting magnetic system (Siemens Magnetom Symphony, Erlangen, Germany) and the whole brain was scanned with a slice thickness of $7 \mathrm{~mm}$ and a 2-mm interslice gap, producing 16 axial images.

DM was diagnosed when a patient had a high fasting plasma glucose $\geq 126 \mathrm{mg} / \mathrm{dl}$ (18) or had been treated with oral hypoglycemic agents or insulin. Hypertension was defined as a systolic pressure $>140 \mathrm{mmHg}$ and/or a diastolic pressure $>90 \mathrm{mmHg}$ on more than one occasion, according to the Joint National Committee (JNC 7) report guidelines (19), and the current taking of anti-hypertensive medications. Smokers were defined as those who were smoking at the time of examination.

As controls, gender- and age-matched healthy subjects were selected from individuals who presented at the Bundang CHA General Hospital for a health examination during the same period. These individuals had no history of myocardial infarction or cerebrovascular disease. The Institutional Review Board of Bundang CHA General Hospital approved this genetic study in October 2003. All patients and controls were Korean and gave their informed consent prior to enrollment in the study.

Genetic analyses. Genomic DNA was extracted from peripheral blood leukocytes using the G-DEX blood extraction kit (Intron Inc., Seongnam, Korea). Nucleotide changes were determined by polymerase chain reaction (PCR)-restriction fragment length polymorphism analyses using the isolated genomic DNA as a template. PCR for the - $786 \mathrm{~T}>\mathrm{C}$ polymor- phism was performed using the following primers: 5 '-ATG CTC CCA CCA GGG CAT CA-3' (forward) and 5'-GTC CTT GAA TCT GAC ATT AGG G-3' (reverse). DNA was amplified by 35 cycles of denaturing at $94^{\circ} \mathrm{C}$ for $30 \mathrm{sec}$, annealing at $51^{\circ} \mathrm{C}$ for $40 \mathrm{sec}$ and extension at $72^{\circ} \mathrm{C}$ for $40 \mathrm{sec}$. The PCR products were detected by gel electrophoresis after incubation with a restriction endonuclease ( $\mathrm{NgOMIV}$; New England Biolabs, Beverly, MA, USA) at $37^{\circ} \mathrm{C}$ for $16 \mathrm{~h}$.

The primer sequences used to detect the eNOS $4 \mathrm{a} 4 \mathrm{~b}$ polymorphism were 5'-AGG CCC TAT GGT AGT GCC TTT-3' (forward) and 5'-TCT CTT TAG TGC TGT GGT CAC-3' (reverse). DNA was amplified by 35 cycles of denaturing at $94^{\circ} \mathrm{C}$ for $1 \mathrm{~min}$, annealing at $49^{\circ} \mathrm{C}$ for $40 \mathrm{sec}$ and extension at $72^{\circ} \mathrm{C}$ for $40 \mathrm{sec}$. The PCR products were visualized by gel electrophoresis. The primers used to detect the $894 \mathrm{G}>\mathrm{T}$ polymorphism were 5'-CAT GAG GCT CAG CCC CAG AAC-3' (forward) and 5'-AGT CAA TCC CTT TGG TGC TCA C-3' (reverse). PCR reactions were run for 35 cycles as follows: $95^{\circ} \mathrm{C}$ for $45 \mathrm{sec}, 63^{\circ} \mathrm{C}$ for $45 \mathrm{sec}$ and $72^{\circ} \mathrm{C}$ for $45 \mathrm{sec}$. The products were digested with a restriction endonuclease (MboI; New England Biolabs) at $37^{\circ} \mathrm{C}$ for $16 \mathrm{~h}$ and detected by gel electrophoresis.

Statistical analysis. Clinical characteristics were compared using the Student's unpaired t-test. The distribution of genotypes for each polymorphism was assessed for deviation from Hardy-Weinberg equilibrium, and differences in genotype frequency and allele frequency between groups were assessed using $\chi^{2}$ tests. A value of $\mathrm{P}<0.05$ was considered statistically significant. StatsDirect Statistical Software version 2.4.4 (StatsDirect Ltd., Altrincham, UK) was used to calculate the adjusted odds ratio (AOR) and 95\% CI. Haplotype analysis was performed using SNPAlyze version 5.1 Standard/Pro (Dynacom Co., Ltd, Yokohama, Japan).

\section{Results}

Table I shows the demographic and clinical characteristics of the subjects enrolled in the study. Both IS patients and controls were sub-grouped according to type $2 \mathrm{DM}$ status. No significant differences in gender or age existed between the sub-groups. Smoking status did not differ between the subgroups, but hyperlipidemia was higher in the controls and in 
Table II. Endothelial nitric oxide synthase polymorphisms in ischemic stroke patients and controls with diabetes mellitus.

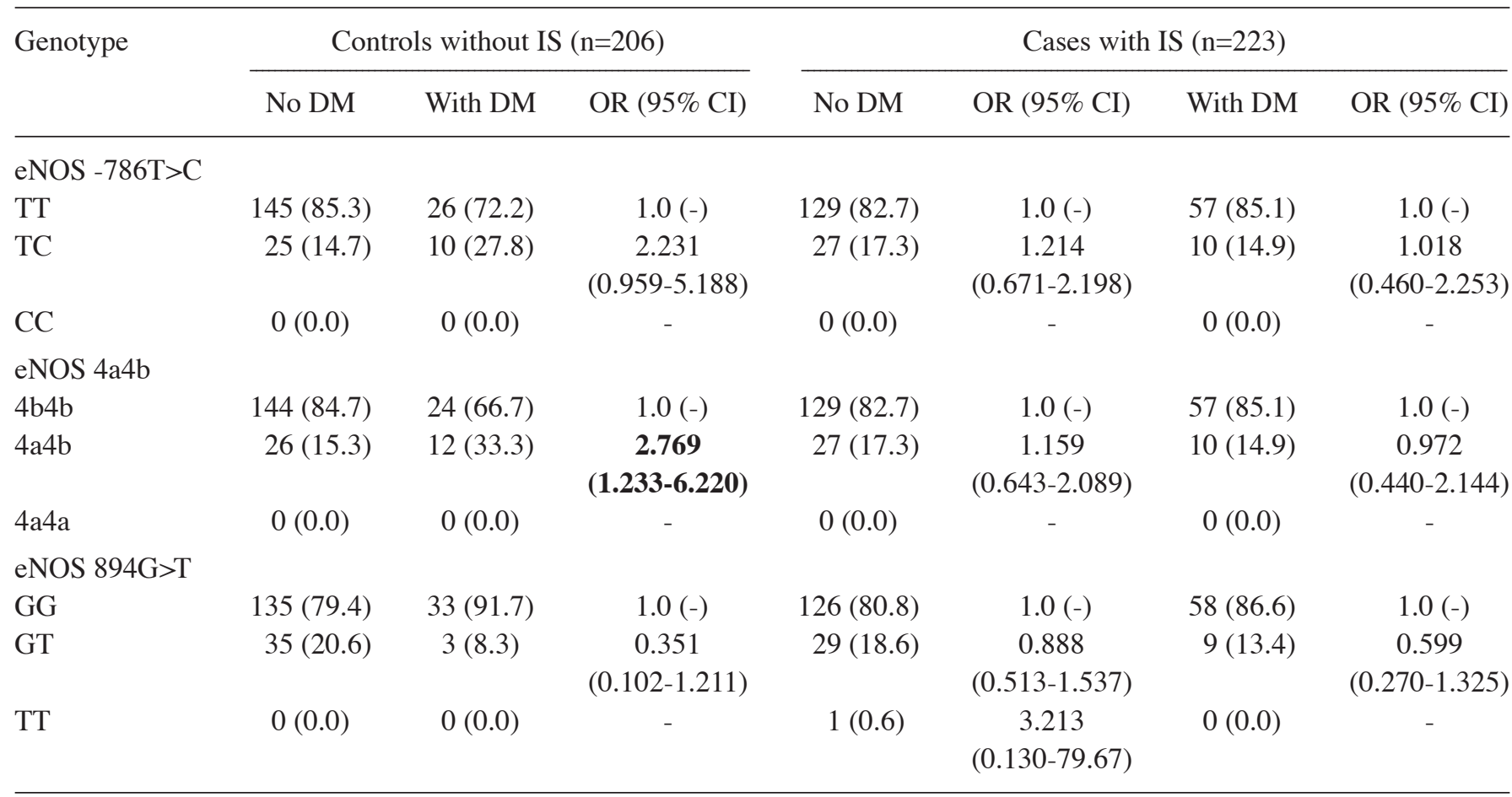

eNOS, endothelial nitric oxide synthase; IS, ischemic stroke; DM, diabetes mellitus. Values in bold are significant.

Table III. eNOS haplotypes in ischemic stroke patients and controls with diabetes mellitus.

\begin{tabular}{lcccrrrr}
\hline Haplotype & Controls (no DM) & Controls (with DM) & Cases (no DM) & Cases (with DM) & p1 & p2 & p3 \\
\hline T-4b-G & 0.821 & 0.792 & 0.815 & 0.835 & 0.555 & 0.821 & 0.719 \\
T-4b-T & 0.099 & 0.042 & 0.086 & 0.067 & 0.119 & 0.559 & 0.272 \\
C-4a-G & 0.067 & 0.139 & 0.064 & 0.052 & $\mathbf{0 . 0 4 0}$ & 0.898 & 0.536 \\
T-4a-G & 0.006 & 0.028 & 0.011 & 0.023 & 0.085 & 0.482 & 0.104 \\
C-4b-G & 0.003 & $5.91 \mathrm{E}-11$ & 0.011 & 0.023 & 0.644 & 0.216 & $\mathbf{0 . 0 3 4}$ \\
C-4a-T & 0.004 & 0.004 & 0.009 & 0.0 & 0.606 & 0.376 & - \\
C-4b-T & $3.61 \mathrm{E}-77$ & 0.000 & 0.002 & 0.0 & - & 0.398 & - \\
T-4a-T & $2.923 \mathrm{E}-87$ & 0.000 & 0.002 & 0.0 & - & 0.398 & - \\
\hline
\end{tabular}

p1, controls without DM vs. controls with DM; p2, controls without DM vs. cases without DM; p3, controls without DM vs. cases with DM. eNOS, endothelial nitric oxide synthase; IS, ischemic stroke; DM, diabetes mellitus. Values in bold are significant.

the IS with DM group $(\mathrm{P}<0.05)$. In addition, hypertension was significantly higher in the control group with DM compared to the control group without DM $(\mathrm{P}=0.027)$, in contrast to the comparison of the IS sub-groups.

Three eNOS gene polymorphisms $(-786 \mathrm{~T}>\mathrm{C}, 4 \mathrm{a} 4 \mathrm{~b}$ and $894 \mathrm{G}>\mathrm{T}$ ) were genotyped. The genotype frequencies of all polymorphisms were in accordance with Hardy-Weinberg equilibrium in the cases and control groups (data not shown). As shown in Table II, the genotype frequency of $4 \mathrm{a} 4 \mathrm{~b}$ in controls with DM was significantly different from that in the controls without DM (4b4b vs. 4a4b; OR=2.769; 95\% CI 1.233-6.220). No predisposition to DM was shown with the $-786 \mathrm{~T}>\mathrm{C}$ and $894 \mathrm{G}>\mathrm{T}$ polymorphisms in either the controls or IS cases.
The haplotype analysis of the three polymorphisms was examined in the four groups (Table III). The -786T-4a-894G haplotype ranged from 79 to $83 \%$ in all sub-groups, and was the most common form observed in this study. The frequency of the -786C-4a-894G haplotype was higher in the controls with $\mathrm{DM}$ than in the controls without $\mathrm{DM}(\mathrm{P}=0.040)$. Additionally, the $-786 \mathrm{C}-4 \mathrm{~b}-894 \mathrm{G}$ haplotype was more common in the cases with $\mathrm{DM}$ than in the controls without $\mathrm{DM}(\mathrm{P}=0.034)$.

\section{Discussion}

$\mathrm{NO}$ is a molecule with pluripotent effects in various tissues and plays an important role in cerebrovascular regulation. $\mathrm{NO}$ is produced by eNOS, and its polymorphisms have 
been reported to be associated with the development of IS. However, the results of studies on the subject have been inconsistent $(15,16,20)$. In addition, DM is associated with a substantially increased risk of total and most subtypes of stroke (21). To date, most association studies have focused on the effect of polymorphisms in the eNOS gene for IS alone (20). Since DM is one of the known predisposing factors to IS, we hypothesized that an eNOS polymorphism or haplotype is associated with susceptibility to IS in patients with DM. The results of this association study with four groups demonstrate that the frequency of genotypes and haplotypes with the $4 \mathrm{a}$ allele in intron 4 is associated with the status of DM, but not with IS. Additionally, the frequency of $-786 \mathrm{C}-4 \mathrm{~b}-894 \mathrm{G}$ in the patients with DM differed significantly from that in the controls without DM.

Song et al (22) studied genotype-specific influences on NOS protein concentration and enzyme activity in vitro, and showed that protein expression and enzyme activity were lower in the $4 \mathrm{a} 4 \mathrm{~b}$ genotype than in the $4 \mathrm{~b} 4 \mathrm{~b}$ genotype. The authors suggested that this effect may be mediated by the $-786 \mathrm{~T}>\mathrm{C}$ polymorphism in the promoter region, since the 4a allele is highly linked to the $-786 \mathrm{C}$ allele in the Korean population $(22,23)$. Consistent with this, in the present study significant differences in the eNOS $4 \mathrm{a}$ allele and in $-786 \mathrm{C}-4 \mathrm{a}-894 \mathrm{G}$ haplotype distributions were observed in controls with type 2 DM compared to those without.

In agreement with the present study, Ohtoshi et al (24) showed that type 2 diabetic patients with the $-786 \mathrm{C}$ allele had a lower plasma NO concentration than non-diabetic subjects, and implied that the -786T $>$ C polymorphism impairs endothelial NO production, resulting in a decrease in insulinmediated glucose uptake due to impaired vasodilatation and poor glycaemic control (24). However, the study did not find a significant association between the -786 $\mathrm{T}>\mathrm{C}$ polymorphism and type $2 \mathrm{DM}$ in the Japanese population studied. We too found no association between the -786T $>C$ genotype frequencies of IS patients with or without DM and those of the controls, but the frequency of the -786C-4b-894G haplotype was significantly different in the IS cases with DM compared to the controls.

This finding suggests that the $-786 \mathrm{C}$ allele is not an independent predisposing factor for IS, but rather may have an additive effect with another allele on the predisposition of patients with DM to IS. However, to validate this observation, a large sample size will be required to clearly demonstrate the effect of two polymorphisms in this group, since the frequency of the haplotype was rare in our population. This is the first report to identify an association between eNOS polymorphisms and IS in patients with type $2 \mathrm{DM}$, even though eNOS polymorphisms for type $2 \mathrm{DM}$ complications are available.

\section{Acknowledgements}

This study was supported by the Korea Research Foundation Grant funded by the Korean Government (2009-0070341).

\section{References}

1. Murray CJ and Lopez AD: Mortality by cause for eight regions of the world: global burden of disease study. Lancet 349: 1269-1276, 1997.

2. Voetsch B and Loscalzo J: Genetic determinants of arterial thrombosis. Arterioscler Thromb Vasc Biol 24: 216-229, 2004.

3. Jorgensen H, Nakayama H, Raaschou HO and Olsen TS: Stroke in patients with diabetes. The Copenhagen Stroke Study. Stroke 25: 1977-1984, 1994.

4. Iso H, Imano H, Kitamura A, Sato S, Naito Y, Tanigawa $T$, Ohira T, Yamagishi K, Iida M and Shimamoto T: Type 2 diabetes and risk of non-embolic ischaemic stroke in Japanese men and women. Diabetologia 47: 2137-2144, 2004.

5. Janghorbani M, Hu FB, Willett WC, Li TY, Manson JE, Logroscino G and Rexrode KM: Prospective study of type 1 and type 2 diabetes and risk of stroke subtypes: the Nurses' Health Study. Diabetes Care 30: 1730-1735, 2007.

6. Garg UC and Hassid A: Nitric oxide-generating vasodilators and 8-bromo-cyclic guanosine monophosphate inhibit mitogenesis and proliferation of cultured rat vascular smooth muscle cells. J Clin Invest 83: 1774-1777, 1989.

7. Moncada S: The L-arginine: nitric oxide pathway, cellular transduction and immunological roles. Adv Second Messenger Phosphoprotein Res 28: 97-99, 1993.

8. Wolf A, Zalpour C, Theilmeier G, Wang BY, Ma A, Anderson B, Tsao PS and Cooke JP: Dietary L-arginine supplementation normalizes platelet aggregation in hypercholesterolemic humans. J Am Coll Cardiol 29: 479-485, 1997.

9. McVeigh G, Brennan G, Johnston D, McDermott BJ, McGrath LT, Henry WR, Andrews JW and Hayes JR: Impaired endotheliumdependent and independent vasodilation in patients with type 2 (non-insulin-dependent) diabetes mellitus. Diabetologia 35: 771-776, 1992.

10. McVeigh G, Brennan G, Hayes JR and Johnston D: Primary nitrate tolerance in diabetes mellitus. Diabetologia 37: 115-117, 1994.

11. Markus HS, Lythgoe DJ, Ostegaard L, O'Sullivan M and Williams SC: Reduced cerebral blood flow in white matter in ischaemic leukoaraiosis demonstrated using quantitative exogenous contrast based perfusion MRI. J Neurol Neurosurg Psychiatry 69: 48-53, 2000.

12. Adachi T and Wang XL: Association of extracellular-superoxide dismutase phenotype with the endothelial constitutive nitric oxide synthase polymorphism. FEBS Lett 433: 166-168, 1998.

13. Hassan A, Gormley K, O'Sullivan M, Knight J, Sham P, Vallance P, Bamford $\mathbf{J}$ and Markus H: Endothelial nitric oxide gene haplotypes and risk of cerebral small-vessel disease. Stroke 35: 654-659, 2004.

14. Yamaguchi S, Yamada Y, Metoki N, Yoshida H, Satoh K, Ichihara S, Kato K, Kameyama T, Yokoi K, Matsuo H, Segawa T, Watanabe S and Nozawa Y: Genetic risk for atherothrombotic cerebral infarction in individuals stratified by sex or conventional risk factors for atherosclerosis. Int J Mol Med 18: 871-883, 2006.

15. Berger K, F Stogbauer F, Stoll M, Wellmann J, Huge A, Cheng S, Kessler C, John U, Assmann G, Ringelstein EB and Funke H: The glu298asp polymorphism in the nitric oxide synthase 3 gene is associated with the risk of ischemic stroke in two large independent case-control studies. Hum Genet 121: 169-178, 2007.

16. Cheng J, Liu J, Li X, Yu L, Peng J, Zhang R, Geng Y and Nie S: Effect of polymorphisms of endothelial nitric oxide synthase on ischemic stroke: a case-control study in a Chinese population. Clin Chim Acta 392: 46-51, 2008.

17. Yamada Y, Kato K, Oguri M, Yoshida T, Yokoi K, Watanabe S, Metoki N, Yoshida H, Satoh K, Ichihara S, Aoyagi Y, Yasunaga A, Park H, Tanaka M and Nozawa Y: Genetic risk for atherothrombotic cerebral infarction in individuals stratified by sex or conventional risk factors for atherosclerosis. Int $\mathrm{J}$ Mol Med 21: 801-808, 2008.

18. Chobanian AV, Bakris GL, Black HR, Cushman WC, Green LA, Izzo JL Jr, Jones DW, Materson BJ, Oparil S, Wright JT Jr and Roccella EJ: The seventh report of the Joint National Committee on prevention, detection, evaluation and treatment of high blood pressure: the JNC 7 report. JAMA 289: 2560-2572, 2003.

19. American Diabetes Association: Diagnosis and classification of diabetes mellitus. Diabetes Care 27: S5-S9, 2004. 
20. Bersano A, Ballabio E, Bresolin N and Candelise L: Genetic polymorphisms for the study of multifactorial stroke. Hum Mutat 29: 776-795, 2008.

21. Sun Q, Ma J, Campos H, Hankinson SE, Manson JE, Stampfer MJ, Rexrode KM, Willett WC and Hu FB: A prospective study of trans fatty acids in erythrocytes and risk of coronary heart disease. Circulation 115: 1858-1865, 2007.

22. Song J, Yoon Y, Park KU, Park J, Hong YJ, Hong SH and Kim JQ: Genotype-specific influence on nitric oxide synthase gene expression, protein concentrations, and enzyme activity in cultured human endothelial cells. Clin Chem 49: 847-852, 2003.
23. Yoon S, Shin C, Park HY, Moon J, Kim E, Kim HT, Min J, Jo SA and Jo I: Endothelial nitric oxide synthase gene is associated with vessel stenosis in Korean population. Clin Clin Chim Acta 353: 177-185, 2005.

24. Ohtoshi K, Yamasaki Y, Gorogawa S, Hayaishi-Okano R, Node K, Matsuhisa M, Kajimoto Y and Hori M: Association of (-)786T-C mutation of endothelial nitric oxide synthase gene with insulin resistance. Diabetologia 45: 1594-1601, 2002. 
